\title{
A UNIVERSIDADE DE ELITE OU PARA TODOS? ${ }^{1}$
}

\author{
José Carlos Rothen \\ Universidade Federal de São Carlos (UFSCar) \\ josecarlos@ rothen.pro.br
}

\begin{abstract}
RESUMO:
O artigo parte da hipótese de que o Conselho Federal de Educação (CFE) - órgão colegiado vinculado ao Ministério da Educação e com poderes normativos - participou efetivamente da elaboração da legislação da Reforma Universitária de 1968. Durante a década de 1960, buscou, via jurisprudência estabelecida por seus pareceres, elaborar uma Reforma. Tem-se por objetivo resgatar os pressupostos e os argumentos nos quais os Conselheiros fundamentavam a posição da constituição de uma universidade de elite. Parte significativa dos debates no interior do CFE foi publicada na Revista Brasileira de Estudos Pedagógicos, editada pelo Instituto Nacional de Estudos Pedagógicos, órgão vinculado ao Ministério da Educação. As matérias divulgadas pelos Conselheiros nessa revista, entre os anos de 1962 (ano de instalação do Conselho) e 1968 (ano da reforma), constituem a fonte primária utilizada. Conclui-se que os conselheiros consideravam a expansão da educação superior como um falso problema; segundo eles, a resposta a essa questão acarretaria em um crescimento desordenado do sistema e na reprodução de um modelo de universidade que já não atenderia às necessidades do país. A verdadeira questão seria exatamente de como controlar a expansão.

Palavras-chave: Expansão da educação superior. Reforma Universitária. Conselho Federal de Educação.
\end{abstract}

\section{AN ELITIST UNIVERSITY OR AN UNIVERSITY FOR ALL?}

\begin{abstract}
:
The start point of this paper is the hypothesis that the Federal Council of Education - a boarding department linked to the Ministry of Education, and with normative powers effectively participated in the elaboration of the University legislation Reform in 1968. The aim of this work is revisited presumptions and arguments used by Counselors in order to write the reform document that resulted in an elitist University education proposal. A significant part of the debates was published by the National Institute of Pedagogic Studies - Ministry of Education, in the Revista Brasileira de Estudos Pedagógicos. The subjects published by the Counselors, between 1962 (Council's establishment year) and 1968 (reform's year), constitute the primary source. As a conclusion of this work it is pointed out that the counselors considered the expansion of the university education a fictitious problem. According to them the hypothetical answer to that deceptive problem would conduct either to a disordered growth of the system or to the reproduction of a university model that would no longer assist the needs of the country. Thus the legitimate problem would be how to control the expansion

Keywords: Higher education expansion. University Reform. Federal Council of Education
\end{abstract}


Em 1968, na fase mais dura da ditadura militar, realizou-se, no Brasil, uma Reforma Universitária, com duplo objetivo: dar uma resposta ao movimento estudantil e à classe média sobre a reivindicação da expansão do ensino superior, bem como atender à aspiração da implantação de uma Universidade de excelência. O resultado foi a criação de um modelo dual: o de excelência e o de consumo.

Este trabalho parte da hipótese de que o Conselho Federal de Educação (CFE) órgão colegiado vinculado ao Ministério da Educação e com poderes normativos participou efetivamente da elaboração da legislação da Reforma e que ,durante a década de 1960, buscou, via jurisprudência estabelecida por seus pareceres, elaborar uma Reforma. Aqui se tem por objetivo resgatar os pressupostos e os argumentos nos quais os Conselheiros fundamentavam a posição da constituição de uma universidade de elite.

Parte significativa dos debates no interior do CFE foi publicada na Revista Brasileira de Estudos Pedagógicos, editada pelo Instituto Nacional de Estudos Pedagógicos, órgão vinculado ao Ministério da Educação. As matérias divulgadas pelos Conselheiros nessa revista, entre os anos de 1962 (ano de instalação do Conselho) e 1968 (ano da reforma), constituem a fonte primária utilizada.

Este trabalho é dividido em dois momentos: no primeiro, será apresentado o contexto sócio-econômico no qual é elaborada a reivindicação da expansão de vagas; no segundo, serão apresentados os princípios nas quais o Conselho fundamenta a tese de que a expansão deve ser controlada.

\section{Desenvolvimento econômico, desigualdades sociais e mobilidade social}

O processo de industrialização brasileiro teve como subproduto a consolidação e o aumento das diferenças sociais. As pessoas que exerciam cargos de direção, gerência e chefia mantiam salários equivalentes aos pagos nos países centrais (SINGER, 1986, p. 232), enquanto que os outros trabalhadores sofriam política de contenção salarial, principalmente após 1964. A diferença salarial entre esses dois grupos de trabalhadores era cada vez maior e, conseqüentemente, estabeleceu-se diferente padrão de consumo. Segundo Marini (2000, p. 82),

[...] a modernização tecnológica [...] depois da guerra de 1939 [...] levou a que se produzisse uma forte margem entre os excedentes de mão-deobra liberados da agricultura e as possibilidades de emprego criadas pela indústria [...] já que esta mão-de-obra só pode ser empregada em certas atividades que exijam pouca qualificação de trabalho (a construção civil, por exemplo), aumentando sua incapacidade profissional ao mesmo ritmo que avança a modernização tecnológica.

O perfil dos que tinham os mais altos padrões de renda, segundo Wilnês Henrique (1999, p. 99), era "morar na cidade, ou ser homem, ou ter atividade urbana, ou ser empregador, ou ter 40 ou mais anos de idade, ou ter 15 anos ou mais de instrução." Ainda conforme a autora:

A atribuição de responsabilidade ao perfil dessa mão-de-obra pela criação de um volume maior ou menor de empregos nas empresas, como se o 
problema da reprodução de um excedente de mão-de-obra no meio urbano decorresse de um descompasso entre as características pessoais e os requisitos dos postos de trabalho exigido pela industrialização (e, muitas vezes, atribuindo ao próprio trabalhador a responsabilidade por portar essas características) imiscuiu-se recorrentemente no pensamento conservador, reaparecendo 'modernamente' no debate sobre a empregabilidade (HENRIQUE, 1999, p. 66, nota de rodapé).

Com base nessa interpretação, para diminuir as diferenças, sociais bastaria expandir o setor moderno da indústria e melhorar a escolarização dos trabalhadores. Henrique aponta que essa interpretação é falsa, pois,

Nessas circunstâncias, a plena definição no pós 1964 de uma estratégia de expansão baseada no aprofundamento da concentração de renda e na difusão do crédito, garantindo a liderança dos setores produtores de bens de consumo duráveis promovendo a modernização selvagem da agricultura, restringiu as possibilidades de uma integração mais favorável do conjunto de trabalhadores no meio urbano, e não apenas daquele excedente de mão-de-obra que vinha do meio rural (HENRIQUE, 2000, p. 69).

A falta de qualificação generalizada da população brasileira implicava que aqueles que tinham qualificação escolar conseguiam melhores resultados na concorrência entre os indivíduos na busca das funções que asseguravam melhor rentabilidade. Pelo exposto, o simples processo de escolarização/qualificação da sociedade não garantiria o fim da grande diferenciação social. O modelo industrial exportador limitava o número de indivíduos que seriam inseridos na sociedade de consumo de bens de luxo. ${ }^{2}$

A Reforma Universitária ocorreu nesse contexto, no qual a solução que tinha alcance apenas individual - o aumento do grau de instrução - transformou-se em uma reivindicação social, a exigência da expansão do ensino superior.

\section{0 movimento estudantil}

O regime militar encontrou resistência nas universidades e no movimento estudantil, tanto que, logo após o golpe militar, iniciaram-se processos de intervenção e ocupação das Universidades. A preocupação com os protestos estudantis levou, em dezembro de 1967, à instalação de uma comissão - que é conhecida pelo nome do seu presidente, o Coronel Meira Mattos - com a função explícita de estudar e propor diretrizes para a ação governamental diante da crise estudantil (FÁVERO, 1977, p. 60). O relatório final da Comissão Meira Mattos deu maior ênfase à questão estudantil e propôs como forma de desmobilização do movimento estudantil, que fosse realizada uma reforma universitária (GERMANO, 1994, p. 127). A comissão Meira Mattos entendia que o problema dos excedentes nos vestibulares ${ }^{3}$ era um dos motivos que levava o apoio popular ao movimento estudantil (NICOLATO, 1986, p. 267). A comissão concluiu que a reforma universitária tornava-se urgente para que fossem possíveis o controle do movimento estudantil e a expansão do ensino superior.

O ano de 1968 foi marcado pela intensificação da resistência ao regime militar. "Não há, praticamente, uma semana em que não ocorra uma passeata, uma mobilização, 
um acontecimento de grande repercussão" (GERMANO, 1994, p. 115). A atuação intensa do movimento estudantil, que tinha como bandeira a Reforma Universitária, fez com que, em junho de 1968, os militares instituíssem o Grupo de Trabalho da Reforma Universitária para elaborar a proposta de nova legislação para o ensino superior, "como que raciocinando em termos de façamos a reforma antes que outros a façam" (SAVIANI, 1988, p. 86).

\section{A gestação de um modelo elitista}

Do debate que ocorreu no Conselho Federal de Educação (CFE), na década de 1960, sobre o modelo de universidade que seria implantado no Brasil, e publicado na Revista Brasileira de Estudos Pedagógicos (RBEP), serão retomadas, nesta seção, as posições que fundamentaram a proposta de controle da expansão da educação superior.

$\mathrm{Na}$ leitura do material publicado na $R B E P$, identificou-se que: o artigo de Ortega y Gasset, "Misión de la universidad", e o livro "The uses of the University", de Clark Kerr, como fontes paradigmáticas que influenciaram a produção intelectual dos conselheiros do CFE. Dois indícios fundamentam essa identificação: primeiro, várias citações dessas obras nos artigos dos conselheiros, contrariando a prática dos artigos da Revista de não fazer referência às obras utilizadas, segundo, mesmo quando os textos foram utilizados sem a citação da fonte, é possível a identificação de idéias desses autores

\subsection{Faculdade de Cultura}

No texto "Misión de la universidad", publicado em 1930, Ortega y Gasset propôs os termos que deveriam nortear a discussão da reforma universitária espanhola. Entendia que a discussão da reforma deveria partir da definição dos "usos" da universidade, isto somente sendo possível se existisse a compreensão de qual seria a sua missão. As discussões que estavam ocorrendo sobre a reforma universitária teriam dois erros fundamentais. O primeiro seria o de compreender que uma nação é grande porque tem boas escolas e não ao contrário. O segundo erro consistiria em buscar modelos estrangeiros ao invés de construir um modelo próprio, mesmo que esse modelo fosse parecido com o dos outros países (ORTEGA Y GASSET, 1992, p. 315).

Para Ortega y Gasset (1992, p. 318), apesar de conceder que existissem faculdades isoladas, o ensino superior deveria ocorrer nas universidades, visão que foi adotada pelos conselheiros que publicavam na $R B E P$, no período estudado. Dado que a função precípua da universidade seria o ensino, o autor passou a apresentar como o ensino na Espanha era estruturado. Em suas palavras:

Em que consiste este ensino superior oferecido na Universidade a imensa legião de jovens? Duas situações:

A) $\mathrm{O}$ ensino das profissões intelectuais

B) A investigação científica e a preparação de futuros investigadores (ORTEGA Y GASSET, 1992, p. 319).

Ortega y Gasset (1992, p.323) defendia a idéia de que o ensino não poderia ser estritamente profissional e que a formação profissional deveria ser separada da formação do cientista. $\mathrm{O}$ ensino deveria transmitir a cultura, e a formação profissional não poderia 
resumir-se à especialização, pois, além do exercício da atividade profissional, o estudante também deveria saber mandar, isto é, exercer a autoridade.

A transmissão da cultura far-se-ia necessária, pois por meio dela é que o homem teria contato com as idéias vivas do seu tempo sobre o mundo (ORTEGA Y GASSET, 1992, p. 321). A ciência seria o maior produto da cultura, mas não seria a cultura. A ciência preocupar-se-ia em levantar problemas que poderiam esperar anos para serem solucionados; a cultura apresentaria as soluções para a vida. Categoricamente, ele afirmou:

Disso a importância de devolver à Universidade sua tarefa central da 'ilustração' do homem, de ensinar-lhe a plena cultura do tempo, de mostrar-lhe com clareza e precisão o gigantesco mundo atual, de encorajá-lo para ter uma vida autêntica (ORTEGA Y GASSET, 1992, p. 344).

Ortega y Gasset não negava que a formação de profissionais e a investigação científica tinham de fazer parte da missão da universidade, mas defendia que a transmissão da cultura, além de fazer parte da sua missão, deveria ser o centro do ensino superior. $\mathrm{O}$ argumento principal em favor da sua tese ele nomeou como "o princípio da economia no ensino". Na explicação deste princípio, ele partiu da constatação de que, diante de alguma limitação, seriam necessárias algumas escolhas. No caso do ensino, o estudante médio teria a sua capacidade de aprender limitada e, por isso mesmo, a universidade precisaria dedicar-se a ensinar o que lhe é necessário para a vida, isto é, a cultura.

A universidade, ao vincular a formação profissional à formação do cientista, ensinaria aquilo que os estudantes não seriam capazes de aprender. A universidade, que seria caracterizada pelo ensino, para atender às necessidades espanholas, deveria enfatizar a cultura (ORTEGA Y GASSET, 1992, p. 348).

\subsection{Multiversidade}

A produção teórica dos conselheiros utilizou como um dos modelos para a construção de saberes o livro de Clark Kerr ${ }^{4}$, intitulado "The Uses of the University", publicado em 1963, que reuniu três conferências proferidas na Universidade de Harvard. O autor defendia a tese de que a universidade americana não tinha característica única, por isso, nomeou-a de multiversidade. A diversidade interna da multiversidade teria como motivo o fato de atender a diversos públicos internos e externos, que formavam comunidades independentes entre si e, muitas vezes, com objetivos distintos (KERR 1982, p. 30-36).

\footnotetext{
A relação da multiversidade com a sociedade seria, ao mesmo, tempo de isolamento e de contato íntimo; ela não seria inteiramente publica e nem privada [...] Ela serveria à sociedade como uma escrava da mesma forma que lhe faria crítica impiedosa (KERR, 1983, p. 19, 30).
}

As diferenças de objetivos das comunidades que constituiriam a multiversidade acarretariam no problema de como estabelecer o diálogo e a unidade da multiversidade. Kerr (1983, p. 31) ironizou, afirmando que se correria o risco de o único fator de unidade ser um estacionamento em comum, onde todos se interligariam apenas na reclamação pela falta de vagas. 
Kerr compreendia que a unidade da multiversidade dependeria da liderança e da mediação do Reitor. As efetivas liderança e mediação somente seriam possíveis se as características do Reitor fossem múltiplas, ou seja, com muitas faces. "Mediador" seria a palavra chave que caracterizaria o Reitor da multiversidade. Kerr defendia que seria mais importante para o Reitor saber mediar os interesses e objetivos das comunidades interna e externa do que ter um plano, isto é, criar novos modelos e objetivos para a universidade.

As características que a universidade norte-americana apresentava, no ano de 1963, segundo Kerr (1982, p. 49), eram conseqüências de dois impactos externos provenientes do governo federal exigindo que ela atendesse às necessidades nacionais. O primeiro, a Lei Morrill, assinada por Abrahan Lincoln, que previa a doação de terras para serem vendidas para fins educacionais. Segundo Kerr, a universidade deixou de formar a elite americana para formar todos os jovens que se qualificassem para tanto. Além de formar o cavalheiro culto e os profissionais para as diversas áreas, a universidade voltou-se para o desenvolvimento industrial e agrícola, realizando pesquisas. O segundo choque ocorreu durante a segunda guerra mundial: o governo federal apoiou pesquisas relacionadas com os conhecimentos bélicos. Esse movimento não foi encerrado com o fim da guerra. $\mathrm{O}$ governo federal, por meio das agências de financiamento, continuou a apoiar os laboratórios que atendiam às necessidades nacionais (KERR, 1982, p. 50). Com ironia, Kerr comentou que a universidade americana atendeu com prontidão à iniciativa federal, apesar do seu orgulho em relação à autonomia.

Para Kerr, os impactos externos seriam fundamentais para que ocorressem mudanças na Universidade. Na terceira conferência intitulada "O futuro da cidade do intelecto", o autor generalizou a sua interpretação da universidade americana para o caso daquelas dos outros países. Em suas palavras:

As mudanças verdadeiramente importantes ocorridas na vida universitária foram iniciadas de fora, por forças como Napoleão, na França; ministros da educação, na Alemanha; comissões reais e a comissão de financiamento à universidade, na Grã-Bretanha; o Partido Comunista, na Rússia; o imperador na época da Restauração, no Japão; os conselhos leigos de dirigentes universitários e o Congresso Federal, nos Estados Unidos - e também, nos Estados Unidos, pelas fundações (KERR, 1982, p. 91).

O último aspecto a ressaltar-se, no livro de Clark Kerr, que constituiu o modelo adotado pelos conselheiros que publicaram na $R B E P$, é o aspecto elitista da universidade. Apesar de a Universidade ter de atender às necessidades de conhecimentos da sociedade $\mathrm{e}$ de ter de atender, a cada ano, um número maior de estudantes, ela não deixaria de ser elitista. $\mathrm{O}$ autor entendia que a igualdade na sociedade norte-americana seria a igualdade de oportunidades e não a igualdade em si mesma.

\subsection{Os problemas considerados legítimos pelo CFE}

Nos textos analisados, de José Ortega y Gasset e de Clark Kerr, os conselheiros encontraram as questões fundamentais para o debate da Reforma Universitária. Ortega y Gasset (1992, p. 317) apontava que o aspecto mais importante era o de se saber qual seria a missão da universidade. Kerr (1982, p. 68) considerava que o grande problema a ser 
resolvido seria a conciliação entre o aspecto elitista da universidade e as exigências da igualdade de oportunidades.

Nas matérias publicadas pelos Conselheiros na RBEP, as questões de Ortega y Gasset e de Clark Kerr foram desdobradas em quatro: 1) a definição de modelo de universidade que atendesse às necessidades de desenvolvimento do país; 2) a definição do tipo de formação de profissional que atendesse às necessidades da indústria; 3) a relação entre o Estado e a Universidade; e 4) a demarcação do nível acadêmico em que deveria ocorrer a pesquisa, isto é, na graduação ou na pós-graduação.

A reivindicação da expansão do ensino superior era considerada, pelos conselheiros que publicavam na $R B E P$, um falso problema. A solução desse problema resultaria na expansão desordenada do sistema e, principalmente, na reprodução de um modelo de universidade que já não atenderia às necessidades do país. Nesse sentido, em depoimento à Comissão Parlamentar de Inquérito da Câmara dos Deputados em 1968, Anísio Teixeira afirmou:

Daí, dizer eu que a expansão do ensino superior é a consolidação do subdesenvolvimento da universidade. Sua expansão, longe de ser uma reforma, é a consolidação do 'estabelecido'. Torna muito mais difícil a reforma! (TEIXEIRA, 1968, p. 49).

Os Conselheiros, ao discutirem o problema da expansão do ensino superior, faziamno em termos contrários ao movimento reivindicatório dos excedentes, isto é, para eles a questão era a de como controlar a expansão do ensino superior. A seguir, tratar-se-á das idéias dos Conselheiros relacionadas com o controle da expansão do ensino superior.

\subsection{Universidades $\mathrm{X}$ faculdades profissionais e o ciclo básico}

Os conselheiros que publicaram na $R B E P$ compreendiam que um dos maiores equívocos da tradição universitária brasileira foi ter-se organizado em torno das faculdades profissionais. Newton Sucupira concebia que, na sua origem, as faculdades profissionais atendiam às demandas da sociedade, mas, com a industrialização, elas se tornaram anacrônicas. Assim argumentou:

\footnotetext{
Enquanto predominavam as estruturas tradicionais da sociedade brasileira, o sistema universitário, baseado nas clássicas faculdades profissionais, atendia facilmente às suas necessidades elementares em matéria de cultura e formação profissional. Com o processo de industrialização e de desenvolvimento econômico que se intensificou na década dos 50 , e as transformações sociais dele decorrentes, logo se tornou patente o anacronismo de nossa universidade (SUCUPIRA, 1968, p. 89).
}

O fundamento da crítica às Faculdades Isoladas era que elas não conseguiam cumprir a missão do ensino superior. As Faculdades profissionais formariam apenas técnicos sem realmente oferecer ensino superior. Valnir Chagas, ao discutir o papel da "faculdade de educação na renovação do ensino superior", afirmou:

[...] o pensamento resulta do 'campo' em que é cultivado; [...] de um contexto de atividades exclusivamente técnicas, como são muitas escolas 
profissionais ditas superiores, outra coisa não surgirá senão uma forma técnica de reagir mentalmente; como surgirá um pensamento científico do estudo bem orientado da ciência e um pensar em geral, científico e especulativo ao mesmo tempo, de um ensino em que se leve em conta a interdependência de 'geral' e 'especial' como expressões do saber em sua fundamental unidade (CHAGAS, 1967b, p. 103-4).

O erro fundamental das Faculdades Profissionais, segundo os conselheiros, repetiuse na organização das Universidades brasileiras, que não passariam de uma confederação de faculdades isoladas. Valnir Chagas, ao elaborar uma retrospectiva histórica sobre as propostas de organização universitária esclareceu:

Em 1920 [...] Outra coisa não se fez, realmente, além de superpor uma reitoria a essas escolas isoladas de caráter exclusivamente profissional, [...] Não se previu sequer a unificação dos estudos comuns e tais áreas de aplicação, e muito menos se cogitou de estabelecer um dispositivo de integração ao nível de conhecimento fundamental (CHAGAS, 1967ª , p. 46).

Valnir Chagas, na sua crítica à educação superior, ressaltava que algumas experiências brasileiras incorporam o verdadeiro espírito universitário. Elogiou a experiência da Universidade de São Paulo (USP), que, na sua fundação, tinha no centro da sua organização a Faculdade de Filosofia, Ciências e Letras, responsável pela sólida formação cultural e científica oferecida aos cursos profissionalizantes. Ressaltou, também, que a Universidade do Distrito Federal, ao ser instalado, em 1935, sob a inspiração de Anísio Teixeira, seguiu um modelo próximo ao da USP (CHAGAS, 1967a, p. 49).

A solução apresentada foi a implantação de um ciclo básico comum a todos os estudantes, desta forma, o professor e o estudante não pertencendo, exclusivamente, a uma faculdade ou a um curso, mas, sim, à Universidade. A idéia de que a Universidade deveria ter um ciclo básico fundamentava-se na concepção de que a precoce especialização do estudante não seria salutar para a formação científica e cultural deles. Valnir Chagas (1967 , p. 46) defendia que a universidade não poderia ser apenas a junção de diversas faculdades profissionais isoladas.

Além da formação científica e cultural dos estudantes, a implantação do ciclo básico diminuiria a pressão para o aumento de vagas nos cursos de maior reconhecimento social, pois o estudante ingressaria na universidade e não no curso, a escolha somente sendo feita após o término do ciclo básico. Anísio Teixeira, em seu depoimento à Comissão Parlamentar de Inquérito (CPI) do ensino superior, exemplificou com o curso de medicina.

Como é a escola de maior prestígio social no Brasil, nenhum aluno corre $\mathrm{o}$ risco de se matricular em outro curso, pois não tem a menor possibilidade de transferir-se para os verdadeiros estudos que o apaixonariam, ou que poderiam vir a apaixoná-lo. Ou entra, de início, na escola de medicina ou jamais entrará nela. [...] Matriculados, iriam todos fazer seus dois ou três anos de cursos básicos, os quais seriam propedêuticos a cursos profissionais, propedêuticos a cursos acadêmicos, de cultura geral ou de carreiras curtas; depois disso é que se iria processar a seleção para as escolas profissionais de carreiras longas e para as diferentes especializações científicas e acadêmicas; uma terceira seleção 
haveria ainda para os cursos avançados pós-doutorais (TEIXEIRA, 1968, p. 48).

Outra vantagem apontada pelos conselheiros, que é explicitado no depoimento acima, de Anísio Teixeira, era que o ciclo básico permitiria a seleção dos melhores estudantes para continuarem os estudos nas carreiras longas. No mesmo sentido, Valnir Chagas, em 1962, no Parecer no 58, ao discutir os exames de seleção, apresentou o Ciclo Básico como um das etapas de seleção. Ele afirmou:

Vencida a etapa do vestibular, duas formas sucessivas de seleção passam a operar-se daí por diante: a seleção para o curso, a ser feito no ciclo básico, e a seleção para a carreira, a ser concluída no curso profissional (CHAGAS, 1962a, p. 17).

Valnir Chagas apontou, ainda, que o Ciclo Básico permitiria a racionalização dos recursos a serem aplicados na educação.

Esta unificação pela base é não somente exequíivel como de grandes vantagens práticas. Para a universidade, ela constitui uma exigência unitária, que repele a dispersão dos recursos materiais e humanos com a manutenção de vários órgãos para uma só função (CHAGAS, 1962a, p. 17).

A postura contrária dos conselheiros às Faculdades Isoladas fundamentava-se na idéia de que essas instituições não atendiam à missão da universidade, isto é, de oferecer formação profissional vinculada à formação cultural.

\subsection{Os recursos limitados e a produtividade da universidade.}

Os conselheiros compreendiam que os recursos para o financiamento da educação eram limitados diante das necessidades educacionais do país. A solução para esse problema seria o de racionalizar os investimentos na educação. Durmeval Trigueiro em 1966, ao discutir o "Plano de Educação no Plano Decenal de Desenvolvimento Econômico", explicou:

A escassez de recursos, humanos e materiais, típica de uma nação que ainda tem mais problemas que meios de resolvê-los, impõe uma severa estratégia de aproveitamento máximo de seus valores disponíveis (TRIGUEIRO, 1966, p. 336).

Durmeval Trigueiro continuou o seu raciocínio defendendo que os recursos da educação não deveriam ser aplicados sem prévio planejamento, e sim, atender às necessidades sociais de desenvolvimento. Valnir Chagas, no Parecer/Indicação 442/66, ao apresentar a proposta de lei que se tornou o decreto-lei $53 / 66^{5}$, defendia que a racionalização dos recursos humanos e materiais permitiriam a superação da escassez de meios para a expansão da educação. Valnir Chagas, ao resumir as partes da sua proposta de lei, enfatizou a concepção de racionalização dos recursos.

A primeira $\left(\operatorname{art.~} 1^{\circ}\right.$ ) fixa os princípios de unidade ensino-pesquisa e nãoduplicação de recursos. A segunda (art. $2^{\circ}$ ) estabelece normas para 
observância daqueles princípios: (I) coexistência de ensino e pesquisa em cada instituto, escola ou faculdade; (II) concentração dos estudos básicos em moldes amplos a que se ajusta qualquer das soluções em curso; (III) exclusividade de cada setor profissional; (IV) institucionalização das atividades interescolares; e (V) supervisão dessas atividades ao nível da administração superior. A terceira parte, finalmente, 'dá outras providências' - as estritamente necessárias - para cumprimento das normas traçadas (CHAGAS, 1966, p. 207-8).

\subsection{O controle da expansão}

Uma das conclusões da Comissão Meira Mattos foi a de que a Lei de Diretrizes e Bases da Educação Nacional (LDB/1961) concedeu amplas atribuições ao Conselho Federal de Educação (CFE), dando-lhe mais poder que ao presidente da República, causando, assim, uma crise de autoridade. O questionamento da Comissão Meira Mattos sobre a atuação do CFE sintetizou uma das questões que o CFE, apesar de formular uma resposta, não considerava um problema legitimo: o ritmo que deveria ter a reforma e quem a faria.

Maurício Rocha e Silva (1966) afirmou que a LDB/1961 já teria os germes da reforma universitária, tanto naquilo que estava explícito, como naquilo em que ela era omissa. Segundo Silva, caberia às universidades formularem suas propostas de regimento interno e ao Conselho Federal de Educação a análise, a crítica e a aprovação das propostas elaboradas. Durmeval Trigueiro, de maneira mais explicita, asseverou que a expansão universitária para não aumentar a mediocridade do ensino universitário, não poderia ser rápida.

Nós não pretendemos impor o ritmo lento em lugar do acelerado que o desenvolvimento reclama; mas o ritmo que desejamos é denso apesar de rápido, enquanto o outro só de pressa [sic] é constituído (TRIGUEIRO, 1967b, p. 209).

Defendia, ainda, que a expansão deveria ocorrer a partir das Universidades já existentes, pois essas poderiam criar uma expansão consistente. O controle da expansão das instituições de ensino superior se fazia necessário, pois a pura e simples expansão das instituições não criaria as condições de uma verdadeira reforma universitária, mas simplesmente expandiria o que deveria ser reformado. Durmeval Trigueiro apontou que oferecer uma educação com baixo índice de qualidade é pior que não oferecer educação alguma.

A falsa educação, estimuladora apenas de impulsos reivindicatórios nos seus titulares, é mais funesta que a ausência de educação formal, já que resta sempre a qualquer indivíduo a possibilidade de assimilar, por indução espontânea, por assim dizer, um certo cabedal mínimo de cultura [...] O pior é alguém julgar-se dissemelhante [sic] da comunidade, por um título falso de educação (que é como um cheque sem fundo), passando a reclamar dela privilégios que não merece (TRIGUEIRO, 1967b, p. 216). 
Em 1962, Valnir Chagas, na sua discussão sobre a "admissão à universidade e a lei de diretrizes e bases", ao defender a criação de cursos de curta duração, assegurou que a expansão que estava ocorrendo era de escolas de baixo nível.

Opondo um dique à proliferação desordenada de escolas de baixo nível, dessas que surgem desde logo completas, ela oferece, todavia, a imediata compensação de um número maior de estabelecimentos que poderão ser criados para o ensino de primeiro ciclo; e ensejando alguma educação superior a muitos brasileiros que, de outra forma, encerrariam os seus estudos em nível médio, ela aumenta a 'oferta' de candidatos aos ciclos profissionais dos cursos superiores, tornando, assim, mais preciso o processo de seleção (CHAGAS, 1962a, p. 18).

Newton Sucupira, no Parecer no qual se tem a "definição dos cursos de pósgraduação", ressaltou a preocupação de que, se não houvesse o controle da expansão da pós-graduação, ela seria aviltada na sua origem.

Por isso mesmo, se quisermos evitar que a pós-graduação brasileira essencial à renovação de nossa universidade - seja aviltada em seu nascedouro, devemos estabelecer não somente princípios doutrinários mas critérios operacionais e normas que dirijam e controlem sua implantação e desenvolvimento. Daí a necessidade de que os cursos de pós-graduação sejam reconhecidos pelo Conselho (SUCUPIRA, 1965, p. 428).

Os critérios da expansão do ensino superior deveriam estar vinculados às demandas de educação do país e não às individuais. Anísio Teixeira, ao analisar, no seu depoimento à CPI do ensino superior, as pressões sociais pela expansão do sistema e os movimentos legítimos de reforma universitária, afirmou:

De um lado, temos a resistência das escolas existentes à mudança, do outro lado, a pressão da população estudantil à ampliação das oportunidades do ensino superior. [...] havia outras empenhadas em reformar o ensino superior para melhor atender aos reclamos do novo tipo de saber necessário à modernização do País e à necessidade de diversificar os estudos para novas carreiras compatíveis com as exigências da nova sociedade em formação. [...] Daí a importância do caso das escolas de Medicina, as quais foram, simultaneamente, as escolas mais resistentes à ampliação da matrícula e as mais progressivas na sua re-organização interna de métodos, conteúdos dos currículos e prática de ensino (TEIXEIRA, 1968, p. 44).

A demanda de educação do país estaria relacionada com as necessidades do seu desenvolvimento econômico. Anísio Teixeira, ao discutir os "aspectos da reconstrução da universidade latino-americana", apresenta a missão da universidade e, conseqüentemente, as demandas a que ela deveria atender:

Se a missão da universidade é contribuir para o desenvolvimento econômico da sociedade, o exemplo de sua organização e de seu método de trabalho, autônomos e responsáveis, será a sua grande contribuição à 
reconstrução democrática desta mesma sociedade (TEIXEIRA, 1967, p. 57).

$\mathrm{Na}$ visão dos conselheiros, a vinculação da educação ao desenvolvimento econômico não implicaria a idéia de que a simples implantação de uma nova universidade iria desenvolver uma região. Ao contrário, é o grau de desenvolvimento regional que indicaria a necessidade ou não da instalação de uma nova escola. Neste sentido, Durmeval Trigueiro enfatizou:

Todo o processo de desenvolvimento e diversificação da educação está condicionado pela estrutura social, e só será eficaz, na medida em que esta for devidamente identificada e enfrentada pelo esforço solidário de todos os setores do Governo, com a colaboração do setor privado. [...] A produção de técnicos de nível superior depende, pois, de pré-requisitos que importem na modificação das condições sócio-econômicas, ou na montagem de aparelhamento técnico-administrativo ajustado às condições típicas de cada região (TRIGUEIRO, 1966, p. 337).

Valnir Chagas reiterou a posição de Durmeval Trigueiro, ao defender que o ensino e a pesquisa deveriam estar relacionados com as necessidades locais:

O ensino e a pesquisa não podem, realmente, deixar de responder a problemas específicos das comunidades, seja preparando os profissionais de que dependem para o seu progresso, seja buscando soluções que permitam maior e melhor utilização dos recursos naturais e humanos para a promoção do bem-estar geral (CHAGAS, 1967b, p. 105).

$\mathrm{O}$ atendimento das reivindicações pela expansão das vagas, ou seja, o atendimento das demandas individuais de ensino superior poderia gerar uma distorção no mercado de trabalho, isto é, formar mais profissionais do que poderiam ser absorvidos, gerando, assim, uma grande massa de desempregados qualificados. Anísio Teixeira assim analisou a situação:

Os alunos das faculdades de Filosofia ainda têm as escolas de nível secundário para lhes oferecer trabalho. Os das faculdades de Economia e Ciências Contáveis bem facilmente poderão estar inflacionando o mercado de diplomados desse campo de trabalho, no caso de não se tornarem eficientes os seus métodos de treinamento técnico (TEIXEIRA, 1968, p. 57).

No controle da expansão do ensino superior e na elaboração e implantação da Reforma Universitária, o CFE teria de exercer função primordial.

\section{Considerações finais}

O modelo de universidade desenhado pelo Conselho Federal de Educação fundamentou-se uma concepção elitista, isto é, de formar apenas os quadros de alto nível que o desenvolvimento do país necessitaria. Na visão do Conselho, a reivindicação da expansão do ensino superior pela classe média reproduziria as Faculdades Profissionais da época, o que seria um equívoco, pois estas não atenderiam à missão da Universidade de transmitir a cultura no seu mais alto nível. 
$\mathrm{Na}$ concepção dos conselheiros, a idéia de igualdade de condições para todos deveria ser interpretada como a igualdade de oportunidades. Nesse sentido, todos teriam a possibilidade de acesso à universidade, mas o efetivo acesso dar-se-ia apenas a uma elite intelectual.

O resultado do embate entre a reivindicação da expansão do ensino superior e a proposta do Conselho Federal de Educação em conter a expansão gerou um modelo de universidade que pretendia vincular o ensino e a pesquisa. Como previsto pelos conselheiros, criou-se um sistema dual de ensino: o de excelência, que se afasta da simples formação de profissionais e o ensino de consumo, que oferece às camadas populares formação profissional deformada, em outras palavras, oferece a ilusão de estarem adquirindo o capital humano necessário para sua ascensão social.

\section{Referências}

CHAGAS, Valnir. A admissão à universidade e a lei de diretrizes e bases. Revista Brasileira de Estudos Pedagógicos, Rio de Janeiro, v. 37, n. 85, p. 8-19, jan/mar, 1962a.

A Luta pela universidade no Brasil. Revista Brasileira de Estudos Pedagógicos, Rio de Janeiro, v. 48, n. 107, p. 44-59, jul./set. 1967a.

Faculdade de educação e a renovação do ensino superior. Revista Brasileira de Estudos Pedagógicos, Rio de Janeiro, v. 47, n. 105, p. 104-115, jan/mar. 1967b.

Reestruturação das Universidades Federais. Parecer/Indicação 442/66. Revista Brasileira de Estudos Pedagógicos, Rio de Janeiro, v. 46, n. 103, p. 204-210, jul/set, 1966.

FÁVERO, Maria de Lourdes de Albuquerque. A universidade Brasileira: em busca de sua identidade. Petrópolis, RJ: Vozes, 1977.

GERMANO, José Willington. Estado Militar e educação no Brasil: 1964-1965. 2 ed. São Paulo: Cortez, 1994.

HENRIQUE, Wilnês. $O$ capitalismo selvagem: um estudo sobre desigualdade no Brasil. 1999, 248 f. Tese (Doutorado em Economia) - Instituto de Economia, Universidade Estadual de Campinas/SP, 1999.

HORTA, José Silvério Baia. O Conselho Federal de Educação e o planejamento educacional no Brasil: uma contribuição à história da educação brasileira. 1975. 236 f. Dissertação (Mestrado em Educação). Pontifícia Universidade Católica do Rio de Janeiro. Rio de Janeiro, 1976.

KERR, Clark. Os usos da universidade. Trad. Débora Cândida Dias Soares. Fortaleza: EFC; 1982.

MARINI, Ruy Mauro. Dialética da dependência: uma antologia de Ruy Mauro Marini. Organização e apresentação de Emir Sader. Petrópolis, RJ: Vozes: Buenos Aires: CLACSO, 2000.

NICOLATO, Maria Auxiliadora. A caminho da lei 5.540/68: a participação de diferentes atores na definição da reforma Universitária. 1986. 519 f. Dissertação (Mestrado em Educação) Faculdade de Educação da Universidade Federal de Minas Gerais. Belo Horizonte, 1986 
OLIVEN, Arabela Campos. A paroquialização do ensino superior: a classe média e sistema educacional no Brasil. Petrópolis, RJ: Vozes, 1990.

ORTEGA Y GASSET, José. Misión de la universidad (1930). In: Obras completas. 2 ed.

Madrid: Alianza Editorial; Revistya de Occidente, 1994. Tomo IV, p. 313-353.

SAVIANI, Demerval. Política e Educação no Brasil: o papel do Congresso Nacional na legislação do ensino. 2 ed. São Paulo: Cortez: Autores Associados, 1988.

SILVA, Maurício Rocha e. Repercussões da lei de diretrizes e bases na organização do ensino superior. Revista Brasileira de Estudos Pedagógicos, Rio de Janeiro, v. 45, n. 101, p. 124-134 jan/mar, 1966.

SINGER, Paul. Interpretação do Brasil: uma experiência histórica de desenvolvimento. In:

FAUSTO, Boris (Dir). História geral da civilização brasileira: o Brasil Republicano. 4. Economia e Cultura (1930-1964). 2 ed. São Paulo: Difel, 1986. p. 211-45.

SUCUPIRA, Newton. A reestruturação das Universidades Federais. Revista Brasileira de Estudos Pedagógicos, Rio de Janeiro, v. 50, n. 111, p. 83-95, jul/set, 1968.

- Definição dos cursos de pós-graduação. Revista Brasileira de Estudos Pedagógicos, Rio de Janeiro, v.44, n. 100, p. 415-433, out/dez, 1965.

TEIXEIRA, Anísio. Aspectos da reconstrução da universidade latino-americana. Revista Brasileira de Estudos Pedagógicos, Rio de Janeiro, v.42, n. 105, p. 55-67, jan/mar, 1967.

Uma perspectiva de Educação Superior no Brasil. Revista Brasileira de Estudos Pedagógicos, Rio de Janeiro, v. 50, n. 111, p. 21-82, jul/set, 1968.

TRIGUEIRO, Durmeval. Expansão do ensino superior. Revista Brasileira de Estudos Pedagógicos, Rio de Janeiro, v. 48, n. 108, p. 209-234, out/dez. 1967b

Governo da universidade. Revista Brasileira de Estudos Pedagógicos, Rio de Janeiro, v. 42, n. 105, p. 68-90, jan/mar, 1967a.

Plano de Educação no Plano Decenal de Desenvolvimento Econômico. Revista Brasileira de Estudos Pedagógicos, Rio de Janeiro, v.46, n. 104, p. 335-350, out/dez, 1966.

\footnotetext{
${ }^{1}$ Este artigo é uma versão revisada do texto apresentado com o mesmo título na V Congresso Brasileiro de História da Educação

2 Sobre a constituição da classe média brasileira, as suas aspirações e a reivindicação da expansão do ensino superior, ver o livro de Arabela Campos Oliven (1990) intitulado "a paroquialização do ensino superior"

${ }^{3}$ Horta (1975, p. 179) esclarece, definindo, o excedente era "aquele que tivesse sido habilitado, mas não tivesse sido selecionado". A não seleção de um candidato ocorria pelo fato do número de vagas ser menor que o número de candidatos habilitados.

${ }^{4}$ Nesse período Clark Kerr era reitor da Universidade da Califórnia.

${ }^{5}$ O decreto-lei 53/1966, em conjunto com o 252/1967, reformou as Universidades Federais Brasileiras, antecipando vários aspectos adotadas na Reforma de 1968.
}

Artigo recebido em: 09/03/2009

Aprovado para publicação em: 26/07/2009

Revista HISTEDBR On-line, Campinas, n.37, p. 109-122, mar.2010 - ISSN: 1676-2584 